\title{
Genomic structure and expression of uncoupling protein 2 genes in rainbow trout (Oncorhynchus mykiss) Issa Coulibaly ${ }^{1,2}$, Scott A Gahr ${ }^{2}$, Yniv Palti ${ }^{2}$, Jianbo Yao ${ }^{1}$ and Caird E Rexroad III*2
}

\author{
Address: ${ }^{1}$ West Virginia University, Animal and Veterinary Sciences Division, Po Box 6108, Morgantown, WV 26506, USA and ${ }^{2}$ National Center \\ for Cool and Cold Water Aquaculture, USDA-ARS, Leetown, WV 25430, USA \\ Email: Issa Coulibaly - icoulibaly@ncccwa.ars.usda.gov; Scott A Gahr - sgahr@ncccwa.ars.usda.gov; Yniv Palti - ypalti@ncccwa.ars.usda.gov; \\ Jianbo Yao - Jianbo.Yao@mail.wvu.edu; Caird E Rexroad* - crexroad@ncccwa.ars.usda.gov \\ * Corresponding author
}

Published: 09 August 2006

BMC Genomics 2006, 7:203 doi:10.1/86/147/-2164-7-203

This article is available from: http://www.biomedcentral.com/I47/-2/64/7/203

(C) 2006 Coulibaly et al; licensee BioMed Central Ltd.

This is an Open Access article distributed under the terms of the Creative Commons Attribution License (http://creativecommons.org/licenses/by/2.0), which permits unrestricted use, distribution, and reproduction in any medium, provided the original work is properly cited.

\begin{abstract}
Background: Uncoupling protein 2 (UCP2) belongs to the superfamily of mitochondrial anion carriers that dissociate the respiratory chain from ATP synthesis. It has been determined that UCP2 plays a role in several physiological processes such as energy expenditure, body weight control and fatty acid metabolism in several vertebrate species. We report the first characterization of UCP2s in rainbow trout (Oncorhynchus mykiss).

Results: Two UCP2 genes were identified in the rainbow trout genome, UCP2A and UCP2B. These genes are $93 \%$ similar in their predicted amino acid sequences and display the same genomic structure as other vertebrates (8 exons and 7 introns) spanning $4.2 \mathrm{~kb}$ and $3.2 \mathrm{~kb}$, respectively. UCP2A and UCP2B were widely expressed in all tissues of the study with a predominant level in macrophage-rich tissues and reproductive organs. In fry muscle we observed an increase in UCP2B expression in response to fasting and a decrease after refeeding in agreement with previous studies in human, mouse, rat, and marsupials. The converse expression pattern was observed for UCP2A mRNA which decreased during fasting, suggesting different metabolic roles for UCP2A and UCP2B in rainbow trout muscle. Phylogenetic analysis including other genes from the UCP core family located rainbow trout $U C P 2 A$ and $U C P 2 B$ with their orthologs and suggested an early divergence of vertebrate UCPs from a common ancestor gene.

Conclusion: We characterized two UCP2 genes in rainbow trout with similar genomic structures, amino acid sequences and distribution profiles. These genes appeared to be differentially regulated in response to fasting and refeeding in fry muscle. The genomic organization and phylogeny analysis support the hypothesis of a common ancestry between the vertebrate UCPs.
\end{abstract}

\section{Background}

In living cells, most energy is produced in the mitochondria through oxidative phosphorylation. In this process, the electron flow from reduced substrates to oxygen gen- erates an electrochemical proton gradient across the inner membrane. This force drives the proton back into the matrix and results in ATP synthesis from ADP and $P_{i}$. Uncoupling proteins (UCPs), which are members of the 
superfamily of mitochondrial anion-carrier proteins, are capable of dissipating the proton gradient across the inner mitochondrial membrane to generate heat while reducing the efficiency of ATP synthesis [1]. The archetypical UCP1 is expressed in brown adipose tissue of mammals and is involved in non-shivering thermogenesis $[2,3]$. UCP1 mRNA has been recently found in ectothermic organisms such as carp, zebrafish and pufferfish [4]. Homologues of UCP1 (UCP2, 3, 4, 5) have been identified from various tissues in vertebrates [5-7] and plants $[1,8]$.

UCP2 has been described in previous studies to play a role in various physiological processes such as body weight control [9-12], fatty acid metabolism [13,14], control of reactive oxygen species $[15,16]$, and negative regulation of insulin secretion $[17,18]$. No clear thermogenic function has been identified for UCP2 [19] but increases of muscle $U C P 2$ mRNA in response to fasting has been reported in rat [20,21], human [22] and marsupials [23]. UCP2 appeared along with UCP3 to affect energy partitioning, feed efficiency, body mass index and obesity $[6,24]$.

The present study was designed to characterize UCP2 genes in the rainbow trout and investigate their potential as candidate genes affecting traits associated with energy balance and nutrition. To this end, we analyzed the genomic structure, phylogenetic relationships with other UCPs, tissue distribution and expression in muscle of $U C P 2$ in response to fasting.

\section{Results and discussion}

\section{Analysis of cDNA and amino acid sequences}

We identified two similar tentative consensus sequences (TC78216 and TC78217) by homology search for UCP2 in the TIGR rainbow trout gene index (RTGI). Both TC78216 and TC78217 were found to contain full-length coding sequences from clones tcad0009a.o21 and tcad0008a.b11, respectively. An additional cDNA clone (1RT84B23) containing EST CA344639 which is assigned to TC78216 was also picked, purified and sequenced. Full sequences of tcad0009a.021, RT84B23 and tcad0008a.b11 were deposited to GenBank and assigned accession numbers [GenBank: DQ295326, DQ295327 and DQ295328].

Similarity analyses between cDNA sequences revealed that the 1,612-bp 1RT84B23 was 90\% identical with 1,455-bp tcad0009a.o21. An 157-bp insert in 1RT84B23 accounted for the $10 \%$ difference between both sequences. The cDNA clone tcad0008a.b11 was 1418 bp and was $78 \%$ and $88 \%$ similar to 1 RT84B23 and tcad0009a.o21, respectively. For ease of identification, tcad0009a.021 and tcad0008a.b11 were dubbed UCP2A and $U C P 2 B$, respectively.
The deduced amino acid sequences of $U C P 2 A$ and $U C P 2 B$ consist of 304 and 311 amino acid residues, respectively (Figure 1). The peptide sequence deduced from 1RT84B23 is a truncated form of that obtained from tcad0009a.021. The deduced protein, which consisted only of transmembrane domain I and one proton carrier signature, most likely lacks the proton dissipation function as it has been demonstrated that the second transmembrane domain of UCP genes is essential for the anion channel formation [25]. This sequence was therefore discarded from further analysis.

We found $93 \%$ similarity between the UCP2A and UCP2B peptide sequences with both containing six transmembrane domains and three proton carrier signatures which define the general triplicate structure of mitochondrial uncoupling proteins [26]. The purine-binding domain involved in the control of coupling efficiency was also identified. Over the protein conserved domains rainbow trout UCP2A and UCP2B diverged only by one aminoacid at position 189 in transmembrane domain IV. The switch from alanine (UCP2A) to valine (UCP2B) should not make any difference in the three-dimensional structure of the peptides as these are both hydrophobic amino acids. On average, both rainbow trout UCP2s showed $83 \%$ amino acid similarity with zebrafish UCP2 and 78\% amino acid similarity with human, rat and mouse UCP2s. UCP2 and UCP3 have been described to be fairly similar in their peptide sequences and their physiological functions $[23,27,28]$. Our results showed $69 \%$ amino acid similarity between rainbow trout UCP2s and mammalian UCP3s.

The identification of two copies of UCP2 genes in rainbow trout genome is consistent with the ancestral whole genome duplication $[29,30]$ and re-diploidization of salmonidae species. Several genes and microsatellite loci in rainbow trout have been previously described to be present in multiple copies $[31,32]$ and Palti et al. estimated that approximately two-thirds of the rainbow trout genes remained duplicated [33].

\section{Phylogenetic relationships}

We performed a phylogenetic analysis to classify rainbow trout UCP2A and UCP2B and determine their relationships to UCPs from other species (Figure 2). The tree generated included 27 peptide sequences from the UCP gene family retrieved from public databases. Trees with similar topology to that of Figure 2 were drawn when either Minimum Evolution or Unweighted Pair Group algorithms were performed. Both rainbow trout UCP2 duplicates were grouped together with their UCP2 orthologs in the same clade. Fish (D. rerio, C. carpio and O. mykiss) and frog UCP2 peptides were assigned to a specific cluster, with a high bootstrap (87\%), as opposed to mammalian 


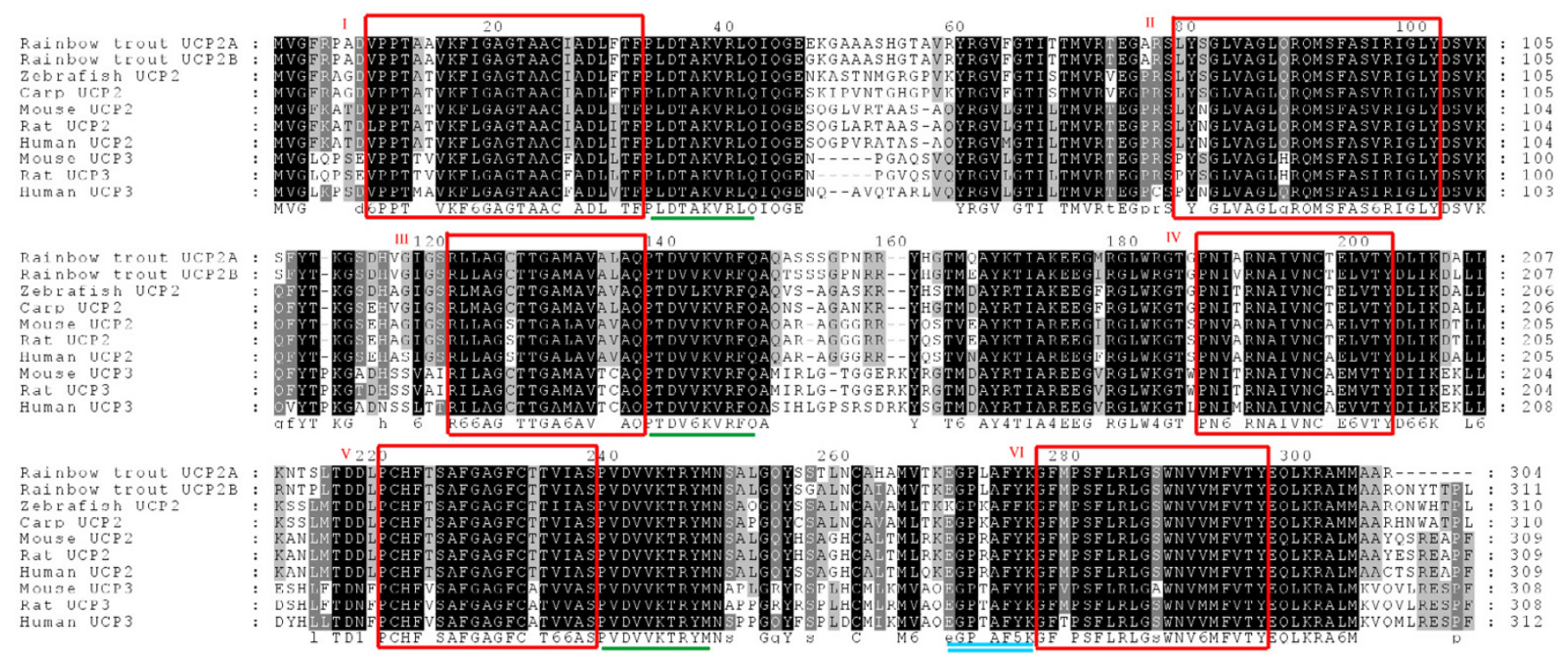

\section{Figure I}

Multiple amino acid sequence alignment of UCP2s. Sequences include human [Genbank: NM 003355], mouse [GenBank: NM 0I I67I], zebrafish [GenBank: NM |3II76], rat [GenBank: AB005|43], carp [GenBank: AJ243486] and rainbow trout [GenBank: DQ295326, DQ295328] and UCP3s from human [GenBank: AACI8822], mouse [GenBank: NP 033490] and rat [GenBank: AB0066I4] obtained using the ClustalW sequence alignment program and illustrated with Genedoc 2.6 [68]. Sequences are presented in single letter code. Gaps, illustrated with a dash, are introduced into sequences to optimize alignment score. Most conserved amino acids are highlighted in black, less conserved ones being in decreasing gray background. Potential transmembrane conserved $\alpha$-helices domains are boxed and numbered in roman numerals. Proton carrier signatures are underlined once and the potential purine binding domain is underlined twice.

UCP2 genes. Our data showed a close relationship between UCP2 and UCP3 in agreement with previous expression patterns and amino acid sequence similarity suggesting that UCP2 and UCP3 are paralogs $[23,27,28]$. Moreover both genes have been mapped on the same chromosome in endothermic vertebrates such as human, bovine, porcine and mouse [34-37] and more recently the same evidence was found in ectothermic vertebrates like zebrafish. [4].

Overall, UCP genes were clustered in three major branches at $100 \%$ bootstrap value leading to three groups consisting of UCP1-3, UCP-4 and UCP-5. We suggest an early divergence of the UCP family gene into three major clades in agreement with the phylogeny described by Sokolova and Sokolov [38]. These authors also demonstrated that this subdivision could be correlated with a functional specialization among the UCP superfamily.

\section{Genomic organization of rainbow trout UCP2}

We identified 32 total BAC clones putatively containing an UCP2 gene of which 16 where specific to UCP2A and 16 were specific to $U C P 2 B$. After fingerprinting, most of these $\mathrm{BAC}$ clones were assembled into three contigs $\mathrm{C} 1$, $\mathrm{C} 2$ and $\mathrm{C} 3$ containing 12, 7 and 2 clones, respectively. C1 consisted of UCP2A-containing BACs while C2 and C3 consisted of $U C P 2 B$-containing BACs. Two representative BACs were selected from each contig for direct sequencing. Two BAC clones, 243P06 and 398G03, were selected from C1 and C3 for further analysis based on their sequence similarities with cDNA clones tcad0009a.o21 (UCP2A) and tcad0008a.b11 (UCP2B), respectively. Genomic sequences for UCP $2 A$ and $U C P 2 B$ genomic sequences have been deposited at NCBI [GenBank: DQ295324, DQ295325].

Alignment between cDNA and BAC genomic sequences revealed the exon-intron structures of UCP $2 A$ and $U C P 2 B$ (Figure 3). In each alignment a TATA box was identified on genomic DNA 47 and 45 bp upstream of the 5 'end of $U C P 2 A$ and $U C P 2 B$, respectively. $U C P 2 A$ and $U C P 2 B$ span $4.2 \mathrm{~kb}$ and $3.2 \mathrm{~kb}$, respectively. Both rainbow trout $U C P 2 \mathrm{~s}$ contain 8 exons and 7 introns. Coding sequences for both genes covered 6 exons as described for mammalian UCP1 [39], UCP2 [40,41] and UCP3 [42] and each exon encodes one transmembrane domain of the protein. The analysis of genomic structure showed that 1RT84B23 is a splice variant of tcad0009a.o21. Exon 4 was 157-bp longer and intron 3 was subsequently 157-bp shorter in 1RT84B23 than in tcad0009a.o21 (Figure 3). Exon 4 of 1RT84B23 is not fully translated as a stop codon is encountered in the first 15 nucleotides. In human where UCP2 has been well 


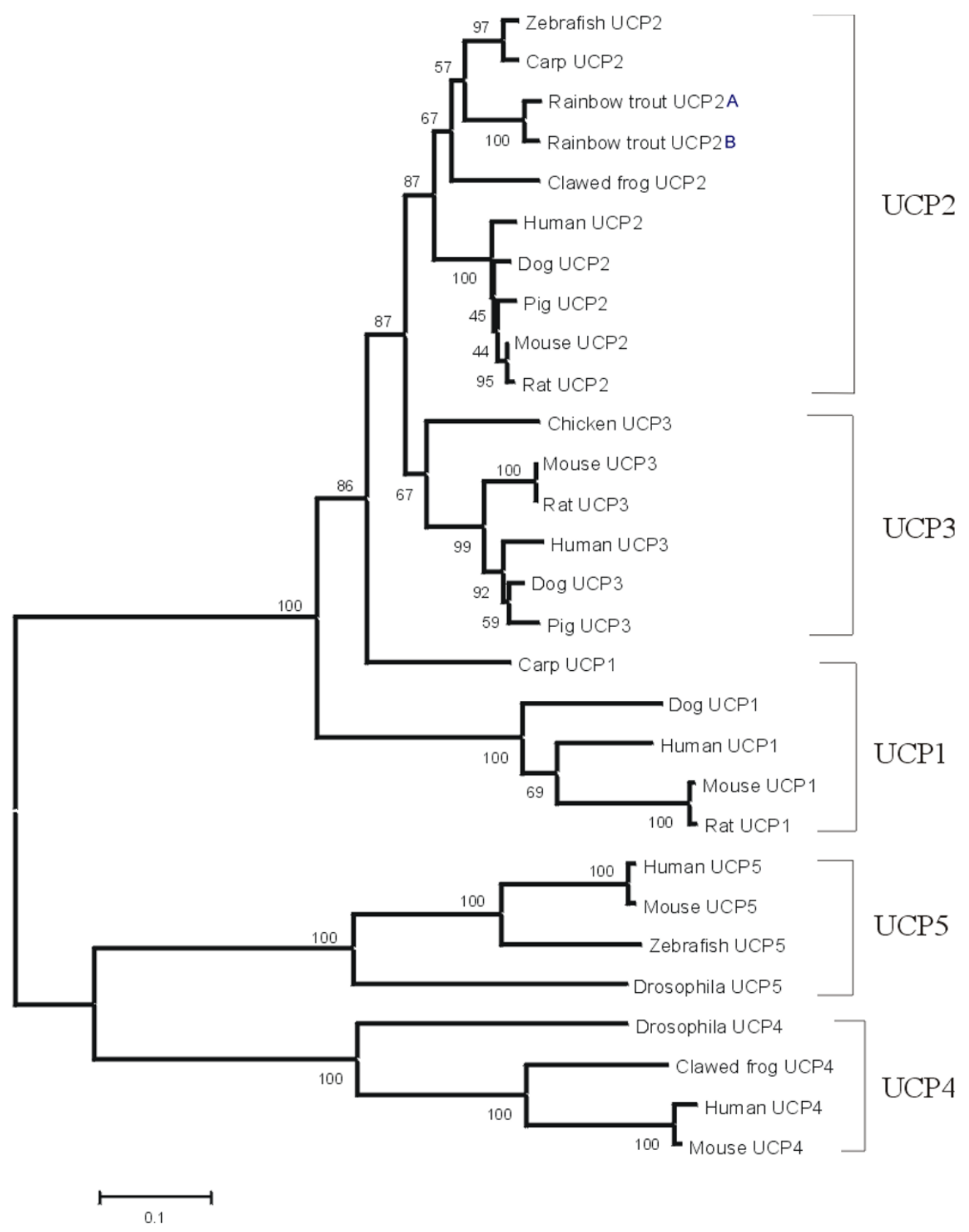

\section{Figure 2}

Evolutionary tree of UCP gene family inferred using the neighbor-joining algorithm. Genetic distance proportional to branch length was calculated based on amino acid difference ( $\mathrm{p}$-distance) with complete deletion of gaps. Bootstrap values computed after I,000 random replications are indicated at tree nodes. Accession numbers for UCPs are: [GenBank: AAH69556, NM 003355, AACI8822, AFI 10532, AF078544] for human (Homo sapiens) UCPI, UCP2, UCP3, UCP4 and UCP5, respectively; [GenBank: NM 009463, AADI7198, NM 009464, NM 0287II, NM 01 I398] for mouse (Mus musculus) UCPI, UCP2, UCP3, UCP4 and UCP5, respectively; [GenBank: NM 012682, AB005I43, AB0066I4] for rat (Rattus norvegicus) UCPI, UCP2 and UCP3, respectively; [GenBank: NM 001003046, AB020887, NM 001003047] for Dog (Canis familiaris) UCPI, UCP2 and UCP3, respectively; [GenBank: NM 131176, BI474135] for Zebrafish (Danio rerio) UCP2 and UCP5, respectively; [GenBank: AASI0175, AJ243486] for Carp (Cyprinus carpio) UCPI and UCP2, respectively; [GenBank: NM 2I4049, AAD088II] for pig (Sus scrofa) UCP2 and UCP3, respectively; [GenBank NM 133018.2, AAK92857] for Drosophila UCP4 and UCP5, respectively; and [GenBank: AAH44682, NM_133018] for frog (Xenopus laevis) UCP2 and UCP4, respectively. 
UCP-2A 4237 bp

(a)

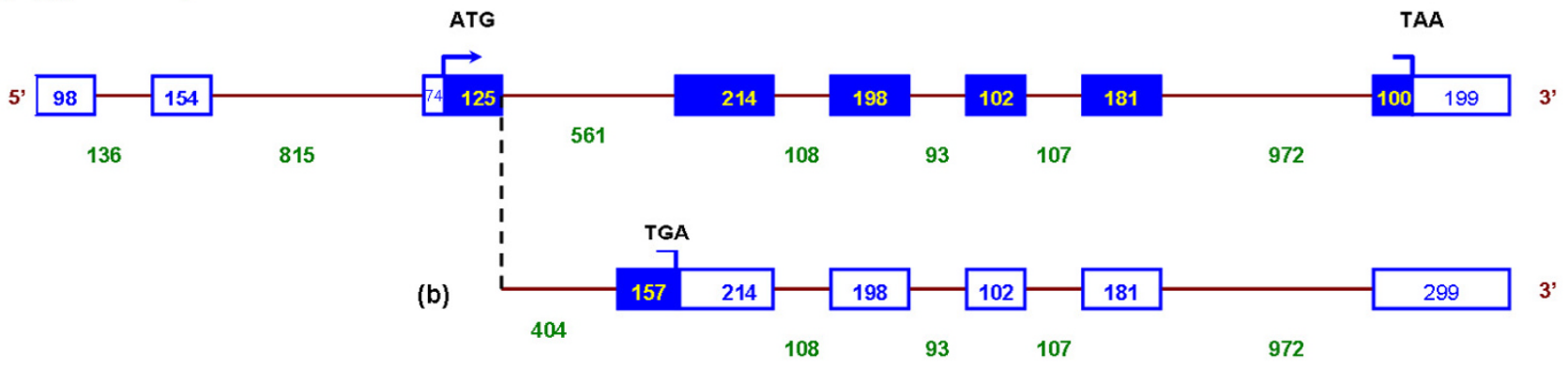

UCP-2B $3213 \mathrm{bp}$

(c)

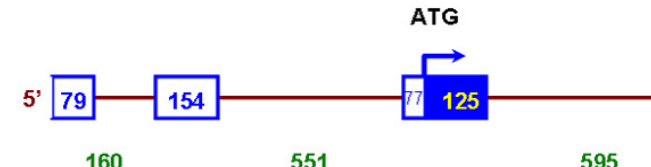

214

107

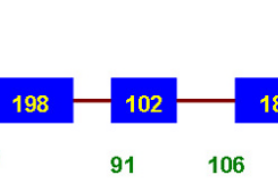

106
3

193

Figure 3

Schematic representation of the exon-intronstructure of UCP2A (a) UCP2A splice variant (b) and UCP2B (c). Lines represent introns, open boxes indicate untranslated exons and shaded boxes represent coding exons. Exon and intron sizes are indicated in base pairs. Exons and introns are not drawn to scale. ATG initiation codon and stop codons are represented by an arrow and a bar, respectively.

characterized, SNP and insertion/deletion variants of the gene were identified [43-45] and no alternative splice variants have been reported to date.

Similarity between $U C P 2 A$ and $U C P 2 B$ was low in the introns with $60 \%$ similarity on average while the average similarity in the exon sequences was $86 \%$. The number and the size of the exons and introns of rainbow trout, human, mouse and zebrafish UCP2s are represented in Table 2. The number of exons was identical in these vertebrate organisms although exon lengths were observed to be somewhat variable. Translated exons 4, 5, 6 and 7 were the most conserved in size between species and within rainbow trout. Exon 7 had the same size in all species. These translated exons showed 93\% average sequence similarity between rainbow trout UCP2A and UCP2B while untranslated exons were 79\% identical. Mutations apparently occur at a slower rate in the coding region than in the untranslated region of duplicated genes. These results show conservation of the structure of UCP2 genes coding exons within vertebrates confirming the hypothesis of a common ancestry for UCP genes.

We examined introns 1 and 2, untranslated exons 1, 2, untranslated part of exon 3 and approximately 300 bp of genomic sequence upstream of each gene's transcription initiation site as the putative promoter regions. This represented 1.6 and $1.3 \mathrm{~kb}$-long sequence upstream of the translation-initiation site (ATG) of $U C P 2 A$ and $U C P 2 B$, respectively. Similarity was $59 \%$ between overlaps suggesting differentiation between regulatory regions of $U C P 2 A$ and $U C P 2 B$. The promoter regions of rainbow trout $U C P 2 A$ and $U C P 2 B$, and the upstream non-coding sequences identified in human $(4.5 \mathrm{~kb})$, mouse $(3.5 \mathrm{~kb})$ and zebrafish $(3.0 \mathrm{~kb})$ UCP2 were searched for regulatory element binding sites using the TFSearch engine version 1.3. The results for ten transcription factors frequently identified are summarized in Tables 3 and 4 . The identification of regulatory conserved motifs upstream of the five genes is consistent with the phylogenetic relationships

Table I: Specific primer sequences for Real-time PCR and corresponding ESTs accession numbers.

\begin{tabular}{|c|c|c|c|c|}
\hline Gene & cDNA clones & EST Accession no. & Forward primer $5^{\prime} \rightarrow 3^{\prime}$ & Reverse primer $5^{\prime} \rightarrow 3^{\prime}$ \\
\hline$U C P 2 A$ & tcad0009a.o21 & [GenBank: $\underline{B X 077844}, \underline{B \times 077845}$ ] & TCCGGCTACAGATCCAGG & CTCTCCACAGACCACGCA \\
\hline$U C P 2 B$ & tcad0008a.bl I & [GenBank: BX079833, BX079834] & TGTAATCACGAGGCATCA & GGATTCTCTAAAGGCGTC \\
\hline $\mathrm{EFI}-\alpha$ & - & [GenBank: AF498320.I] & GGGCAAGGGCTCTTTCAAGT & CGCAATCAGCCTGAGAGGT \\
\hline
\end{tabular}


Table 2: Size in base pairs of UCP2 gene exons and introns. Species include rainbow trout [GenBank: DQ295324, DQ295325], human [GenBank: NC 000011.8 ], mouse [GenBank: NT 039433] and zebrafish [GenBank: NC 007II 6.1 ]

\begin{tabular}{|c|c|c|c|c|c|c|c|c|c|c|c|c|}
\hline \multirow[t]{2}{*}{ No } & \multicolumn{2}{|c|}{ Rainbow trout UCP2A } & \multicolumn{2}{|c|}{ Rainbow trout $U C P 2 B$} & \multicolumn{2}{|c|}{ Human } & \multicolumn{2}{|c|}{ Mouse } & \multicolumn{2}{|c|}{ Zebrafish } & \multirow{2}{*}{$\begin{array}{l}\text { Exon average } \\
\text { length }( \pm S D)\end{array}$} & \multirow{2}{*}{$\begin{array}{l}\text { Intron average } \\
\text { length }( \pm S D)\end{array}$} \\
\hline & Exon & Intron & Exon & Intron & Exon & Intron & Exon & Intron & Exon & Intron & & \\
\hline I & 98 & 136 & 79 & 160 & 125 & 1088 & 103 & 747 & 101 & 125 & $101.2 \pm 16.4$ & $451.2 \pm 443$ \\
\hline 2 & 154 & 815 & 154 & 551 & 156 & 2998 & 162 & 2350 & 145 & 2554 & $154.2 \pm 6.1$ & $1853.6 \pm 1098$ \\
\hline 3 & 199 & 561 & 202 & 595 & 225 & 156 & 223 & 146 & 221 & 2701 & $214 \pm 12.4$ & $831.8 \pm 1067$ \\
\hline 4 & 214 & 108 & 214 & 107 & 211 & 868 & 211 & 772 & 214 & 78 & $212.8 \pm 1.6$ & $386.6 \pm 397$ \\
\hline 5 & 198 & 93 & 198 & 91 & 196 & 80 & 196 & 75 & 195 & $105 \mid$ & $196.6 \pm 1.3$ & $278 \pm 432$ \\
\hline 6 & 102 & 107 & 102 & 106 & 101 & 969 & 102 & 286 & 102 & 80 & $101.8 \pm 0.5$ & $309.6 \pm 378$ \\
\hline 7 & 181 & 972 & 181 & 193 & 181 & 369 & 181 & 319 & 181 & 2710 & $|8| \pm 0.0$ & $912.6 \pm 1049$ \\
\hline 8 & 299 & - & 278 & - & 451 & - & 2787 & - & 286 & - & $820.2 \pm 1101.8$ & - \\
\hline Gene size (bp) & \multicolumn{2}{|c|}{4,237} & \multicolumn{2}{|c|}{3,211} & \multicolumn{2}{|c|}{8,174} & \multicolumn{2}{|c|}{8,660} & \multicolumn{2}{|c|}{10,774} & & \\
\hline
\end{tabular}

previously described between the UCP2 genes in human, mouse, zebrafish and rainbow trout. The binding sites of ADR1, CAP, CdxA and HSF were identified in upstream region of all five genes although at different frequency. AML1a (acute myeloid leukemia), MZF (Myeloid zinc finger protein 42) USF (Upstream Stimulatory Transcription Factor) binding sites were identified in mouse and human sequences and absent in fish (rainbow trout, zebrafish). Among the fish UCP2 genes, the rainbow trout UCP2A regulatory region appeared to be the most unique with almost half of the binding motifs identified in $U C P 2 B$ and zebrafish UCP2. Among the regulatory motifs we identified for UCP2 genes, USF and CREB have been shown to regulate the expression of $U C P 2$ and $U C P 1$, respectively $[47,48]$. Our results suggest, in agreement with previous data in the literature $[49,50]$, that some transcription factor binding sites are conserved across species while others are not.

\section{Tissue distribution and response to fasting}

The distribution of relative expression of rainbow trout $U C P 2 A$ and $U C P 2 B$ was investigated on a panel of 23 tissues from adult fish (Figure 4). Both $U C P 2 A$ and $U C P 2 B$ genes appeared ubiquitously expressed in the body as described in marsupials [23], human [6,46], carp [4] and mouse [7] making the genes likely to influence several physiological processes. The highest relative expression was observed in ovary, peripheral blood leucocytes (PBL), gill, testis, spleen and trunk kidney. In all these tissues except ovary, $U C P 2 B$ mRNA relative amounts were at least twice that of $U C P 2 A$. In brain, fat, pituitary and red blood cells, UCP $2 A$ mRNA was more abundant than $U C P 2 B$ mRNA. High amounts of $U C P 2$ mRNAs in reproductive organs and in tissues rich in macrophages like PBLs, spleen, and kidney have been reported in several studies. Arsenijevic et al. [51] and Kizaki et al. [52] suggested a role for UCP2 in immunity or inflammatory responsiveness

Table 3: Computational identification of putative transcription factor binding sites. Species include rainbow trout (UCP2A Om, UCP2B Om) zebrafish (UCP2 Dr), mouse (UCP2 Mm) and human UCP2 (UCP2 Hs) promoter regions using TFSearch engine version I.3. Number of representations of each transcription factor binding sites are indicated and "-"indicates less than 2 binding sites.

\begin{tabular}{ccccccccccc}
\hline Genes & ADRI & AML-Ia & CAP & CdxA & CREB & HSF & MZFI & Nkx2 & SRY & USF \\
\hline UCP2A Om & 2 & - & 2 & 9 & - & 5 & - & - & - \\
UCP2B Om & 2 & - & 2 & 6 & 3 & 9 & - & 2 & 4 \\
UCP2 Dr & 4 & - & 4 & 18 & - & 24 & - & 3 & - \\
UCP2 Mm & 26 & 2 & 26 & 2 & - & 21 & 4 & 2 & 2 \\
UCP2 Hs & 20 & 5 & 20 & 3 & - & 19 & 3 & 3 & 5
\end{tabular}

ADRI: Alcohol Dehydrogenase Gene Regulator I (S. cerevisiae), activator.

AML-I a: Acute Myeloid Leukemia I; (human); may act as a negative regulator.

Cap: cap signal for transcription initiation signal (vertebrates), activator.

CdxA: chick; Chicken CHox-cad gene for caudal homologue, activator.

CREB: Cyclic-AMP Response Element-Binding Protein, transactivator.

HSF: Heat Shock Transcription Factor (Drosophila), activator.

MZFI: Myeloid Zinc Finger protein MZFI (human); possibly involved in hemopoietic development.

Nkx2: murine homeobox gene (mouse) modest activator probably important for myocardial development.

SRY: Sex-determining Region Y gene product (human, mouse).

USF: Upstream Stimulatory Transcription, activator (mouse). 
Table 4: Location of transcription factor binding sites in the promoter regions of rainbow trout UCP genes. Positions are indicated relative to the translation-initiation site ATG.

\begin{tabular}{|c|c|c|}
\hline Transcription factors & UCP2A & $U C P 2 B$ \\
\hline ADRI & $-707 ;-533$ & $-1070 ;-535$ \\
\hline CAP & $-1045 ;-40$ & $-1268 ;-872$ \\
\hline $\mathrm{CdxA}$ & -||$|88 ;-||| 7|;-820 ;-869 ;-800 ;-74| ;-7 \mid 3 ;-139 ;-14$ & $-1281 ;-1260 ;-947 ;-490 ;-473 ;-119$ \\
\hline CREB & - & $-|091 ;-872 ;-63|$ \\
\hline HSF & $-1044 ;-991 ;-934 ;-238 ;-75$ & $-1162 ;-1112 ;-896 ;-783 ;-731 ;-672 ;-605 ;-449 ;-78$ \\
\hline Nkx2 & - & $-639 ;-259$ \\
\hline SRY & - & $-1253 ;-1106 ;-938 ;-720$ \\
\hline
\end{tabular}

through the regulation of reactive oxygen species in macrophages. In mouse ovary, UCP2 mRNA levels have been described to increase during ovulation as a result of the increasing number of macrophages and neutrophils [53]. In trout, ovaries in maturation are characterized by the presence of many macrophages inside the cytoplasm of the oocytes [54]. The ovaries used in our tissue distribution panel were developing. Therefore, we suggest the high amount of UCP2 mRNA in trout ovary could be due to the macrophage-rich developmental stage of the tissue used.

The initial average weight of the fish used in the current study was $231 \mathrm{mg}$ ( 225 for the fed group and 236 for the fasted group). Following day 14, the fed fish weighed 475 $\mathrm{mg}$ and the fasted fish were $167 \mathrm{mg}$. At day 21 of fasting, termination of the fasted group, the average weight of the fish was $661 \mathrm{mg}, 171 \mathrm{mg}$ and $239 \mathrm{mg}$ for the fed, fasted and refed groups, respectively. Rainbow trout $U C P 2 A$ and $U C P 2 B$ were differentially expressed in response to fasting and refeeding in fry (Figure 5). UCP2A mRNA expression was similar between all groups at the beginning of the experiment. Three days after food deprivation, UCP2A expression was three times higher in fed fish than in fasted fish. The amount of gene expression remained significantly higher in fed fish than in fasted fish until day 21 of the experiment. Refeeding of fasted animals started at day 14 and resulted in a 2-fold increase of UCP2A at day 21. At day 28, refed and fed fish had the same amount of UCP2A expression.

At day $0, U C P 2 B$ expression is similar in all fry. At day 3, expression was 3-fold augmented in fasted fish while no significant increase was found in the fed fish. $U C P 2 B$ expression drastically decreased in fasted fish to the level observed in fed fish at day 7 before a significant increase was observed again at day 14 . At days 14 and 21, UCP2B was expressed higher in fasted fry than in fed fry. In fed animals, no significant differences were noted between $U C P 2 B$ expression levels throughout the experiment, except at day 17. Refed fish showed the same level of expression of the gene as the fasted fish at day 14. UCP2B expression then decreased in refed fish to reach the same level expressed in fed animals at days 21 and 28. The expression pattern of $U C P 2 B$ in response to fasting is consistent with what has been described for other species in the literature. The food deprivation induced-increase in mRNA expression is one of the most spectacular features of UCP2 and UCP3 in rodent and human [20-22,55-58]. The hypothesis is that during fasting when glucose is limiting, upregulation of muscle UCP2 is associated with the shift in muscle substrate utilization primarily towards lipid. On refeeding with a low-fat diet, UCP2 is down regulated allowing the re-use of glucose as major substrate. It has been also demonstrated that a high-fat diet induces up-regulation of UCP2 and UCP3 thus promoting fat utilization over storage $[55,57]$. The actual mechanism of UCP involvement in fatty acid metabolism is not yet fully understood, but Samec et al. [56] established a close relationship between expression of UCP2 and UCP3 and well-known key regulators of lipid oxidation. Our study, unlike most of experiments in the literature, monitored UCP2 mRNA levels for a relatively long fasting time (four weeks). Our results suggest that increase of $U C P 2 B$ mRNA is maintained during the whole fasting time, although the higher expression is detected early.

The overall amount of expression of $U C P 2 B$ genes in fry muscle were much lower than what we observed for $U C P 2 A$. Five times more CDNA was included in Real-time PCR for $U C P 2 B$ primers than was used for $U C P 2 A$ to detect readable amplification signals. As a result, the highest detected amount of $U C P 2 B$ gene EF1-normalized expression is 0.023 compared with that of $U C P 2 A$ which was 18.81. In adult fish, as described above $U C P 2 B$ mRNA expression was much higher relatively to UCP2A mRNA in some of the tissues. In light of the expression data in response to fasting, $U C P 2 B$ is likely the homolog of the $U C P 2$ described in other vertebrates. UCP2A is a duplicate form of the gene that has undergone a different evolutionary process leading to a different expression pattern. This is illustrated by the sequence divergence and different cisregulatory elements identified in the promoter regions of both genes. Further functional characterization of the pro- 


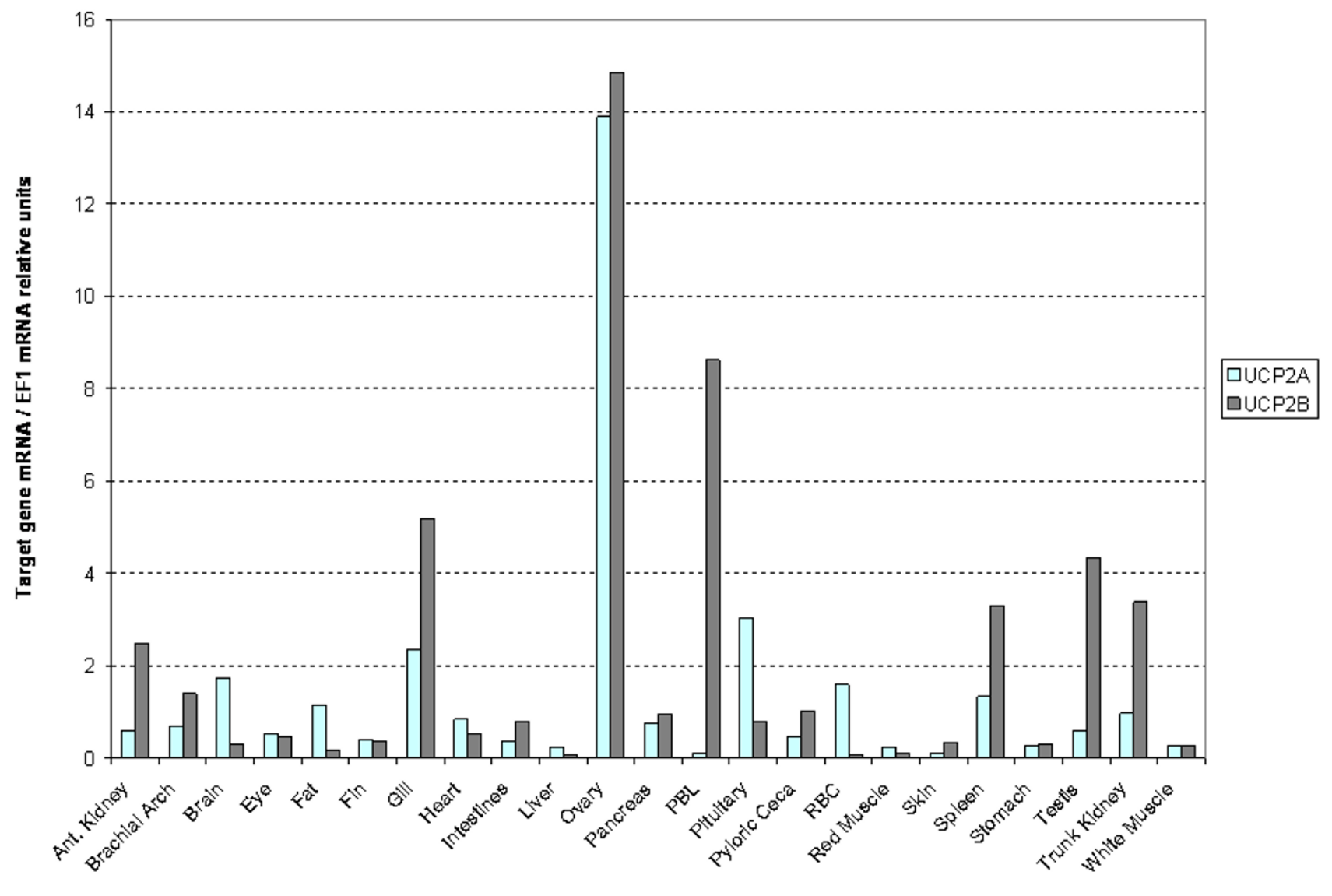

\section{Figure 4}

Tissue distribution of rainbow trout UCP2A and UCP2B mRNA relative expressions estimated by Real-time RT-PCR. Various tissues were collected on 2 years old fish weighting approximately I kg. Gene mRNA values were normalized to EFI. Means values were computed from 3 technical replicates. Abbreviations: PBL: peripheral blood leukocytes; RBC: Red blood cells.

moter region and identification of regulatory motifs could help address the differences between mRNA expression of $U C P 2 A$ and $U C P 2 B$.

\section{Conclusion}

We have identified two UCP2 genes in rainbow trout. Both genes were highly similar at the amino acid level and widely expressed in the body. Analyses of the genomic organization and phylogeny data based on protein sequence similarity suggest a close relationship between members of the UCP superfamily. In rainbow trout fry $U C P 2 A$ and $U C P 2 B$ appeared downregulated and upregulated on fasting, respectively. Further characterization of both genes in different physiological and dietary conditions, and developmental stages will assist in better testing and understanding hypothesis related to their specific functions and differentiation.

\section{Methods}

\section{Search for rainbow trout UCP2 cDNA}

UCP2 sequences from human, mouse and zebrafish UCP2 mRNAs [GenBank: NM 003355.2, NM 011671.2, NM 131176.1] were T-BLASTed against the Rainbow Trout Gene Index [59] to identify putative orthologues from rainbow trout [60].

Identification and fingerprinting of UCP2 gene-containing BAC clones Gene specific primers were designed from putative rainbow trout UCP2 cDNAs identified by homology searches for screening of the NCCCWA Swanson $10 \times$ bacterial artificial chromosome (BAC) library [26] PCR pools according to the manufacturer's directions (Amplicon Express, Pullman, WA). Two sets of primers were designed to screen the BAC library, forward 5'-CACCATGGTGCGTACAGAG-3' and reverse 5'-TTGGGATGGTCTTGTAGG-3'; 


\section{UCP2A}

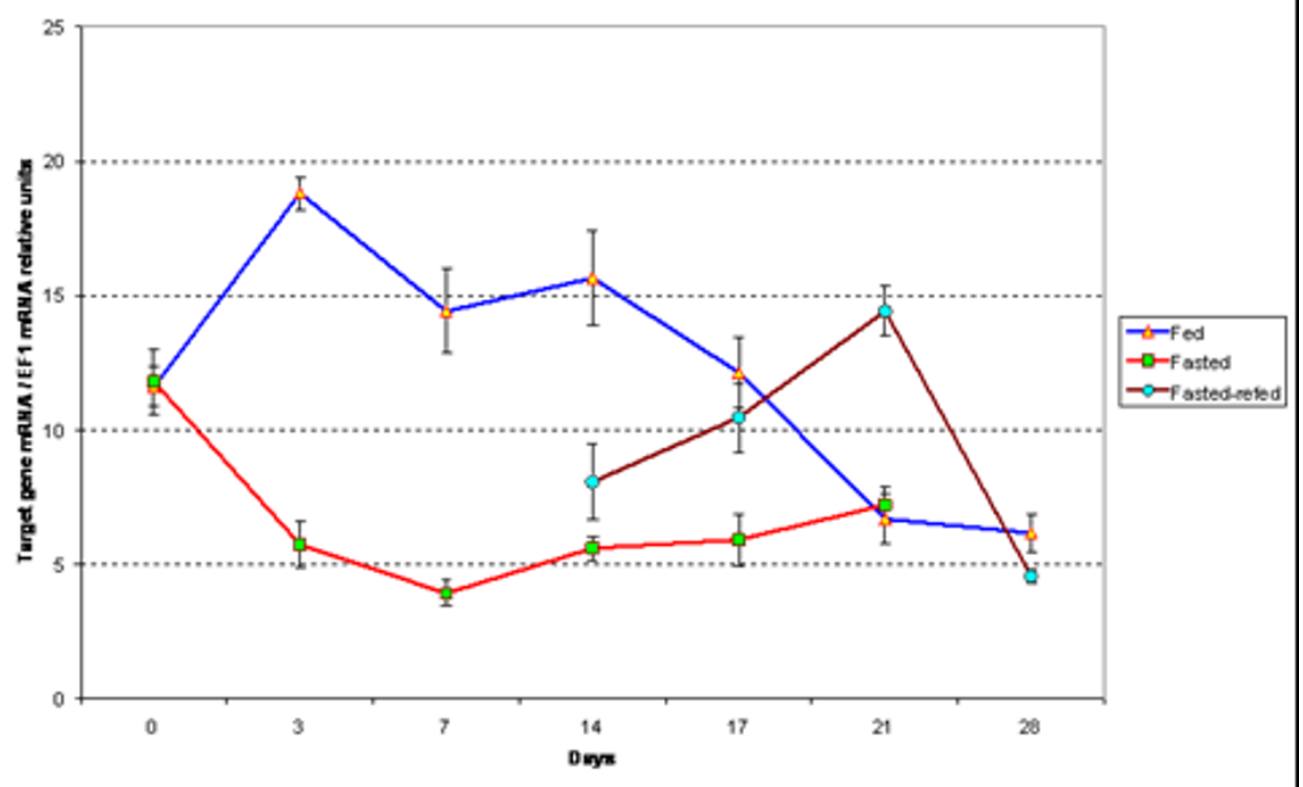

\section{UCP2B}

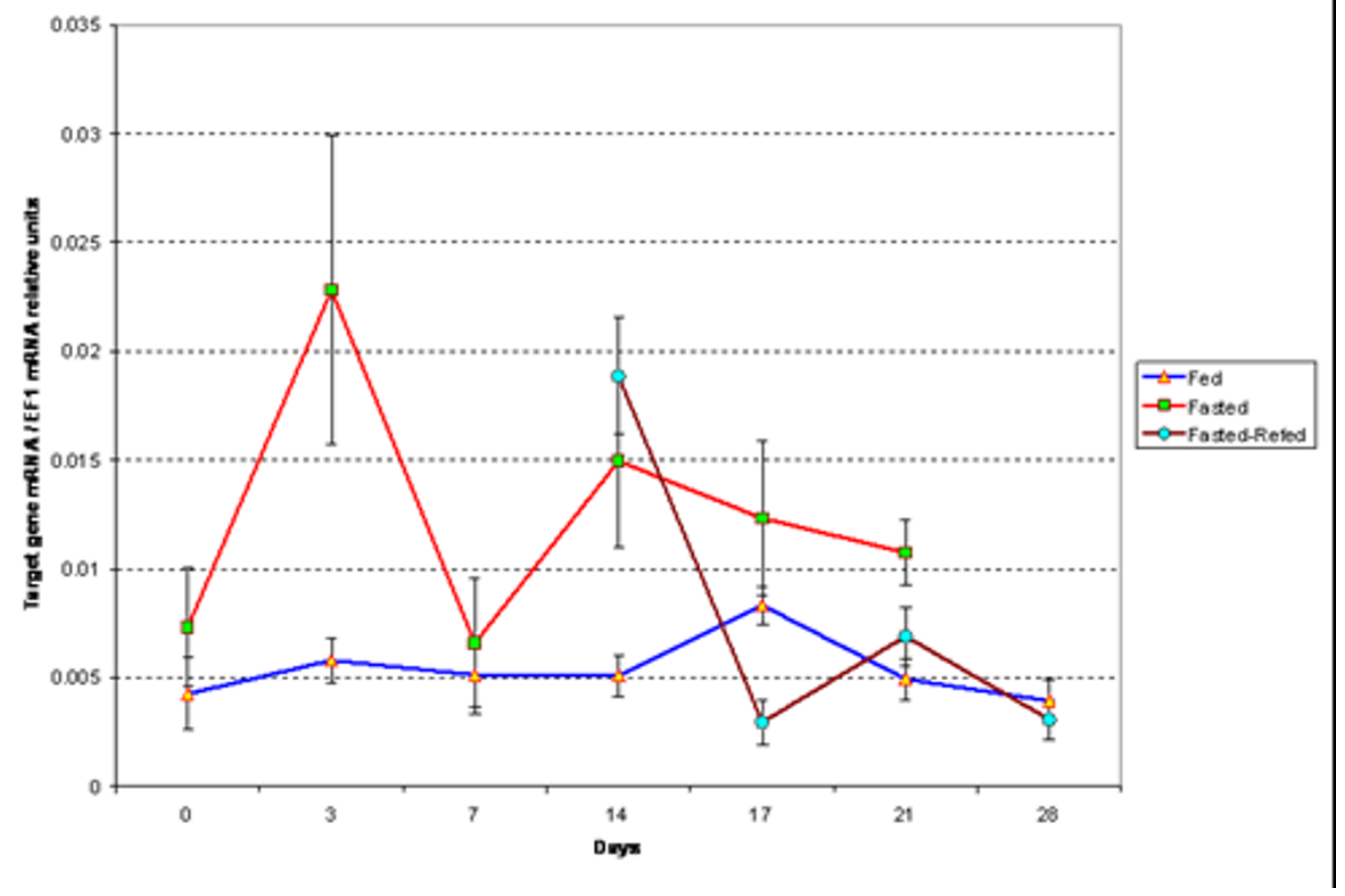

Figure 5

Rainbow trout UCP2A (A) and UCP2B (B) mRNA relative expression. Relative Expression was estimated by Real-time RT-PCR in mixed fiber type muscle of fed and fasted fry at 7 time points after food deprivation and fasted-refed fry at 4 time points on refeeding. Day 0 on chart corresponds to 37 days post hatching for all samples. Data are presented as means \pm SEM $(n=4-6)$ 
and forward 5'-TTTATCGGTGCTGGAACAGC-3' and reverse 5'-TAAGAAGCGCGTCCTTGATG-3'. Primer specificities were checked by alignment between cDNAs and by BLAST against NCBI databases.

BACs identified as positive for UCP2 genes were fingerprinted using HindIII to identify sets of overlapping clones as previously described [33]. BAC DNA was obtained using the Qiagen Large Construct Kit protocol. Following digestion and electrophoresis, gel images were captured using a Molecular Dynamics Typhoon 9210 Variable Mode Imager and exported as TIF files. Banding patterns were analyzed using Image $3.10 \mathrm{~b}$ and FPC (Fingerprinted Contigs) V6 software [61] to assemble overlapping BACs into contigs [62].

\section{Sequence analysis}

DNA sequencing was performed using the Big Dye ${ }^{\circledast}$ Terminator Cycle Sequencing Kit and an ABI3100 automatic sequencer (Applied Biosystems, Foster City, CA). cDNA and genomic sequences were obtained by primer walking. Sequences were analyzed using the Sequencher 4.1 .4 software (Gene Codes Corporation, Ann Arbor, MI, USA). Exon-intron boundaries were identified by locating $5^{\prime}$ donor GT and 3' acceptor AG consensus sequences in a cDNA-genomic DNA gap alignment.

Genomic sequence upstream of the rainbow trout UCP2 gene was obtained in order to perform a computational prediction of cis-acting transcription factor binding sites using the TFSearch engine [63] that uses the TRANSFAC databases. Also for each human, mouse and zebrafish, we downloaded the genomic and mRNA sequences from GenBank and aligned them to retrieve the gene structure and locate the translation-initiation site. The upstream sequences including 300 bp upstream on the genomic sequence were then selected for the prediction of transcription factors binding sites. The identifiers of human, mouse and zebrafish UCP2 genomic sequence obtained are [GenBank: NC 000011.8, NT 039433, NC 007116.1], respectively. Sequence obtained for promoter analysis was located on human chromosome $11 \mathrm{q} 13$ (73,363,064-73,367,806), on mouse chromosome region $7 \mathrm{E} 2(18,239,174-18,242,911)$ and zebrafish chromosome $5(60,833,577-60,836,877)$.

\section{Experiment design and tissue collection}

Experiments were conducted on rainbow trout fry hatched at the National Center for Cool and Cold Water Aquaculture (Leetown, WV). Thirty three fish at 32 days post-hatching $(\mathrm{dph})$ were placed into each of $18 \times 24 \mathrm{~L}$ buckets. The buckets were supplied with flow-through oxygen saturated well water at $12.5+0.2^{\circ} \mathrm{C}$, and a photoperiod of $12 \mathrm{~h}$ light $-12 \mathrm{~h}$ dark. Fish were fed a commercial diet, Finfish Starter Meal, (57\% protein and 15\% fat;
Ziegler Bros. Inc., Gardner PA) at 2\% body weight daily. Fish were divided into three treatment groups: 1) fed fish as controls, 2) fasted fish, and 3) fish fasted the first 14 days of the experiment and re-fed thereafter. The experiment was initiated $37 \mathrm{dph}$, shortly after the completion of yolk-sac absorption. Muscle tissues were collected on days $0,3,7,14,17,21$ and 28 of the experiment. Each tank was only sampled once and fish from two tanks for each treatment were sampled. At sampling, fish were anesthetized with $200 \mathrm{mg} / \mathrm{L}$ Tricaine and mixed fiber type muscle pools from four individuals were excised and immediately frozen in liquid nitrogen then stored at $-80^{\circ} \mathrm{C}$ until RNA extraction. All animal handling and sampling procedures were reviewed and approved by the NCCCWA Institutional Animal Care and Use Committee.

Tissues were collected from branchial arch, brain, eye, fat, gill, heart, intestines, liver, ovary, pancreas, peripheral blood leukocytes, red and white muscles, pituitary, pyloric ceca, red blood cells, skin, spleen, stomach and testis on healthy 2-year old adult fish (approximately $1 \mathrm{~kg}$ in mass) for the survey of UCP2 mRNA expression in the rainbow trout body.

\section{RNA isolation and first strand cDNA synthesis}

Total RNA was extracted using Tri-reagent (Sigma, St Louis, Missouri) according to the manufacturer's protocol. Total RNA was precipitated in ethanol, washed and dissolved in nuclease-free water. RNA was treated with DNAse to eliminate genomic DNA contamination and reextracted using Tri-reagent. RNA concentrations were estimated by spectrophotometry and integrity was checked on agarose gels. First strand cDNA synthesis was performed in a $40 \mu$ reaction volume containing $2 \mu \mathrm{g}$ total RNA, $1 \mu \mathrm{g}$ of Random Hexamer primers, $1 \times \mathrm{M}-\mathrm{MLV}$ reaction buffer, $500 \mu \mathrm{M}$ of dNTPs, 200 units of M-MLV reverse transcriptase (Promega, Madison, USA) and 25 units Recombinant Rnasin ${ }^{\circledR}$ Ribonuclease Inhibitor (Promega, Madison, USA). The mix was incubated at $37^{\circ} \mathrm{C}$ for 60 min with a final denaturation at $95^{\circ} \mathrm{C}$ for $5 \mathrm{~min}$. Reactions were stored at $-20^{\circ} \mathrm{C}$ until further use.

\section{Real-time PCR}

Specific forward and reverse primers were designed for each target and reference gene cDNA (Table 1) on the boundary of two consecutive exons or in intron flanking regions to prevent amplification of contaminating genomic DNA or to make it detectable on a gel. Either way, amplicons were run on gel to confirm their uniqueness and size expectation prior to real-time PCR runs. Real-time PCR was performed in a $15 \mu$ reaction volume containing $1 \mu \mathrm{l}$ of cDNA template, $250 \mathrm{nM}$ of each forward and reverse primers and $7.5 \mu$ l of SYBR Green PCR Master Mix (Applied Biosystems, Foster City, USA). Amplifications were performed on the ABI PRISM 7900 
Sequence Detection System real-time cycler using the following program: $50^{\circ} \mathrm{C}$ for $10 \mathrm{~min}, 95^{\circ} \mathrm{C}$ for $15 \mathrm{~s}, 40$ cycles of $95^{\circ} \mathrm{C}$ for $15 \mathrm{~s}, 60^{\circ} \mathrm{C}$ for $30 \mathrm{~s}, 72^{\circ} \mathrm{C}$ for $30 \mathrm{~s}$ and a dissociation stage at $95^{\circ} \mathrm{C}$ for $15 \mathrm{~s}, 60^{\circ} \mathrm{C}$ for $15 \mathrm{~s}$ and $95^{\circ} \mathrm{C}$ for $15 \mathrm{~s}$. Dissociation curves were analyzed to detect nonspecific amplification. Non-template controls were included in each run and checked for no amplification. The amount of transcript in each sample was quantified using the standard curve method [65]. The standard curve was constructed using 10 dilutions ( 1 to $1 / 1000$ ) of a pool of cDNA. Gene expression in tissues was rendered as a ratio of target gene versus rainbow trout Elongation Factor$1 \alpha(E F 1-\alpha$, GenBank Accession Number AF498320.1) as reference gene. We surveyed EF1- $\alpha, \beta$-actin, TATA box Binding protein $a(T B P-a)$ and $18 S r R N A$ as potential internal control genes for RT-PCR (data not shown). Of the housekeeping genes tested, EF1- $\alpha$ demonstrated the most consistent Ct values between treatments (average $23.7 \pm$ 1.1). EF1- $\alpha$ has been previously demonstrated to be a reliable housekeeper in several tissues of Atlantic salmon [64].

The real time PCR mRNA expression data were analyzed using the Statistica software version 6 (StatSoft. Inc., Tulsa, OK, USA). Differences in UCP2 mRNA expression between treatments were assessed at each time point using the Kruskal-Wallis non-parametric test. A pair wise post hoc comparison of means was performed when difference between treatments was significant at the 0.05 threshold.

\section{Phylogenetic inference}

Twenty seven UCP peptide sequences were identified and retrieved from public databases using keywords and BLAST searches. Multiple sequence alignments were conducted using Clustal W [66]. Sequence alignments were used as an input file to construct a consensus phylogenetic tree by the neighbor joining method using MEGA version 3 [67]. Reliability of tree was assessed by bootstrapping using 1,000 random replications.

\section{Authors' contributions}

IC carried out the molecular genetics studies, sequencing, sequence alignment, statistical analysis, and drafted the manuscript. SAG participated in the gene identification process, designed the experiment and extracted the RNA. YP contributed to the BAC fingerprinting. JY and CER participated in the study design and coordination. All authors read and approved the final manuscript.

\section{Acknowledgements}

We are grateful to Roseanna Long, Kristy Shewbridge and Renee Fincham for their technical assistance and to Dr Greg Weber (NCCCWA, Kearneysville, WV, USA) for his comments and advice. All authors were funded for this study through USDA/ARS/NCCCWA CRIS\# 1930-31000-008 entitled, "Identification and Characterization of Genes Affecting Cool and Cold Water Aquaculture Production."
The experiments performed in this study comply with the current USA laws. Mention of trade names or commercial products in this publication is solely for the purpose of providing specific information and does not imply recommendation or endorsement by the US Department of Agriculture.

\section{References}

I. Ledesma A, de Lacoba MG, Rial E: The mitochondrial uncoupling proteins. Genome Biol 2002, 3:REVIEWS30I5.

2. Nicholls DG: A history of UCPI. Biochem Soc Trans 200I, 29:75I-755

3. Nicholls DG, Rial E: A history of the first uncoupling protein, UCPI. J Bioenerg Biomembr 1999, 31:399-406.

4. Jastroch M, Wuertz S, Kloas W, Klingenspor M: Uncoupling protein $I$ in fish uncovers an ancient evolutionary history of mammalian nonshivering thermogenesis. Physiol Genomics 2005, 22:150-156.

5. Boss O, Samec S, Paoloni-Giacobino A, Rossier C, Dulloo A, Seydoux J, Muzzin P, Giacobino JP: Uncoupling protein-3: a new member of the mitochondrial carrier family with tissue-specific expression. FEBS Lett 1997, 408:39-42.

6. Fleury C, Neverova M, Collins S, Raimbault S, Champigny O, LeviMeyrueis C, Bouillaud F, Seldin MF, Surwit RS, Ricquier D, Warden $\mathrm{CH}$ : Uncoupling protein-2: a novel gene linked to obesity and hyperinsulinemia. Nat Genet 1997, 15:269-272.

7. Ricquier $D$, Bouillaud $F$ : The uncoupling protein homologues: UCPI, UCP2, UCP3, StUCP and AtUCP. Biochem J 2000, 345(Pt 2): $161-179$.

8. Borecky J, Maia IG, Arruda P: Mitochondrial uncoupling proteins in mammals and plants. Biosci Rep 200I, 2I:20I-2I2.

9. Trayhurn P: The biology of obesity. Proc Nutr Soc 2005, 64:3 I-38.

10. Jaberi E: Genetic linkage of uncoupling proteins (UCP2 and UCP3) with body weight regulation. Asia Pac J Clin Nutr 2004, 13:SI 40 .

II. Hagen T, Vidal-Puig A: Mitochondrial uncoupling proteins in human physiology and disease. Minerva Med 2002, 93:4I-57.

12. Schonfeld-Warden NA, Warden CH: Physiological effects of variants in human uncoupling proteins: UCP2 influences bodymass index. Biochem Soc Trans 200I, 29:777-784.

13. Goglia F, Skulachev VP: A function for novel uncoupling proteins: antioxidant defense of mitochondrial matrix by translocating fatty acid peroxides from the inner to the outer membrane leaflet. Faseb / 2003, 17:1585-1591.

14. Jezek P: Fatty acid interaction with mitochondrial uncoupling proteins. J Bioenerg Biomembr 1999, 31 I:457-466.

15. Echtay KS, Murphy MP, Smith RA, Talbot DA, Brand MD: Superoxide activates mitochondrial uncoupling protein 2 from the matrix side. Studies using targeted antioxidants. J Biol Chem 2002, 277:47| 29-47| 35.

16. Negre-Salvayre A, Hirtz C, Carrera G, Cazenave R, Troly M, Salvayre $R$, Penicaud $L$, Casteilla $L$ : A role for uncoupling protein-2 as a regulator of mitochondrial hydrogen peroxide generation. Faseb J 1997, I I:809-8I5.

17. Chan CB, De Leo D, Joseph JW, McQuaid TS, Ha XF, Xu F, Tsushima RG, Pennefather PS, Salapatek AM, Wheeler MB: Increased uncoupling protein-2 levels in beta-cells are associated with impaired glucose-stimulated insulin secretion: mechanism of action. Diabetes 200I, 50:1302-1310.

18. Zhang CY, Baffy G, Perret P, Krauss S, Peroni O, Grujic D, Hagen T, Vidal-Puig AJ, Boss $O, K i m$ YB, et al.: Uncoupling protein-2 negatively regulates insulin secretion and is a major link between obesity, beta cell dysfunction, and type 2 diabetes. Cell 200I, 105:745-755.

19. Golozoubova V, Hohtola E, Matthias A, Jacobsson A, Cannon B, Nedergaard J: Only UCPI can mediate adaptive nonshivering thermogenesis in the cold. Faseb J 200 I, I 5:2048-2050.

20. Boss O, Samec S, Dulloo A, Seydoux J, Muzzin P, Giacobino JP: Tissue-dependent upregulation of rat uncoupling protein-2 expression in response to fasting or cold. FEBS Lett 1997, 4I2: III-II4.

21. Cadenas S, Buckingham JA, Samec S, Seydoux J, Din N, Dulloo AG, Brand MD: UCP2 and UCP3 rise in starved rat skeletal muscle but mitochondrial proton conductance is unchanged. FEBS Lett 1999, 462:257-260.

22. Millet L, Vidal H, Andreelli F, Larrouy D, Riou JP, Ricquier D, Laville $M$, Langin $D$ : Increased uncoupling protein-2 and -3 mRNA 
expression during fasting in obese and lean humans. J Clin Invest 1997, 100:2665-2670.

23. Jastroch M, Withers K, Klingenspor M: Uncoupling protein 2 and 3 in marsupials: identification, phylogeny, and gene expression in response to cold and fasting in Antechinus flavipes. Physiol Genomics 2004, 17: 130-139.

24. Surwit RS, Wang S, Petro AE, Sanchis D, Raimbault S, Ricquier D, Collins S: Diet-induced changes in uncoupling proteins in obesityprone and obesity-resistant strains of mice. Proc Natl Acad Sci USA 1998, 95:406I-4065.

25. Yamaguchi H, Jelokhani-Niaraki M, Kodama H: Second transmembrane domain of human uncoupling protein 2 is essential for its anion channel formation. FEBS Lett 2004, 577:299-304.

26. Krauss $S$, Zhang $C Y$, Lowell $B B$ : The mitochondrial uncouplingprotein homologues. Nat Rev Mol Cell Biol 2005, 6:248-26I.

27. Brand MD, Esteves TC: Physiological functions of the mitochondrial uncoupling proteins UCP2 and UCP3. Cell Metab 2005 2:85-93.

28. Esteves TC, Brand MD: The reactions catalysed by the mitochondrial uncoupling proteins UCP2 and UCP3. Biochim Biophys Acta 2005, I 709:35-44.

29. Venkatesh B: Evolution and diversity of fish genomes. Curr Opin Genet Dev 2003, 13:588-592.

30. Bailey GS, Poulter RT, Stockwell PA: Gene duplication in tetraploid fish: model for gene silencing at unlinked duplicated loci. Proc Natl Acad Sci USA 1978, 75:5575-5579.

31. Coulibaly I, Gharbi K, Danzmann RG, Yao J, Rexroad CE 3rd: Characterization and comparison of microsatellites derived from repeat-enriched libraries and expressed sequence tags. Anim Genet 2005, 36:309-315.

32. Gahr SA, Palti Y, Rexroad CE 3rd: Genomic characterization of a novel pair of ID genes in the rainbow trout (Oncorhynchus mykiss). Anim Genet 2004, 35:317-320.

33. Palti Y, Gahr SA, Hansen JD, Rexroad CE 3rd: Characterization of a new BAC library for rainbow trout: evidence for multilocus duplication. Anim Genet 2004, 35: 130- I33.

34. Pecqueur C, Cassard-Doulcier AM, Raimbault S, Miroux B, Fleury C Gelly C, Bouillaud F, Ricquier D: Functional organization of the human uncoupling protein-2 gene, and juxtaposition to the uncoupling protein-3 gene. Biochem Biophys Res Commun 1999 , 255:40-46.

35. Stone RT, Rexroad CE 3rd, Smith TP: Bovine UCP2 and UCP3 map to BTA I 5. Anim Genet 1999, 30:378-38I.

36. Werner $P$, Neuenschwander S, Stranzinger G: Characterization of the porcine uncoupling proteins 2 and 3 (UCP2 \& UCP3) and their localization to chromosome $9 \mathrm{p}$ by somatic cell hybrids. Anim Genet 1999, 30:221-224.

37. Yoshitomi H, Yamazaki K, Tanaka I: Cloning of mouse uncoupling protein 3 cDNA and 5 '-flanking region, and its genetic map. Gene 1998, 21 5:77-84.

38. Sokolova IM, Sokolov EP: Evolution of mitochondrial uncoupling proteins: novel invertebrate UCP homologues suggest early evolutionary divergence of the UCP family. FEBS Lett 2005, 579:3 I3-317.

39. Ricquier $D$, Bouillaud $F$ : The mitochondrial uncoupling protein: structural and genetic studies. Prog Nucleic Acid Res Mol Biol I997, 56:83-108.

40. Argyropoulos G, Brown AM, Peterson R, Likes CE, Watson DK, Garvey WT: Structure and organization of the human uncoupling protein 2 gene and identification of a common biallelic variant in Caucasian and African-American subjects. Diabetes 1998, 47:685-687.

4I. Yamada M, Hashida T, Shibusawa N, Iwasaki T, Murakami M, Monden T, Satoh T, Mori M: Genomic organization and promoter function of the mouse uncoupling protein 2 (UCP2) gene. FEBS Lett 1998, 432:65-69.

42. Solanes G, Vidal-Puig A, Grujic D, Flier JS, Lowell BB: The human uncoupling protein-3 gene. Genomic structure, chromosomal localization, and genetic basis for short and long form transcripts. I Biol Chem 1997, 272:25433-25436.

43. Otabe S, Clement K, Rich N, Warden C, Pecqueur C, Neverova M, Raimbault S, Guy-Grand B, Basdevant A, Ricquier D, et al.: Mutation screening of the human UCP 2 gene in normoglycemic and NIDDM morbidly obese patients: lack of association between new UCP 2 polymorphisms and obesity in French Caucasians. Diabetes 1998, 47:840-842.
44. Lindholm E, Klannemark M, Agardh E, Groop L, Agardh CD: Putative role of polymorphisms in UCPI-3 genes for diabetic nephropathy. J Diabetes Complications 2004, 1 8:103-107.

45. Walder K, Norman RA, Hanson RL, Schrauwen P Neverova M, Jenkinson CP, Easlick J, Warden CH, Pecqueur C, Raimbault S, et al: Association between uncoupling protein polymorphisms (UCP2-UCP3) and energy metabolism/obesity in Pima indians. Hum Mol Genet 1998, 7:1431-1435.

46. Fleury C, Sanchis D: The mitochondrial uncoupling protein-2: current status. Int / Biochem Cell Biol 1999, 31:126I-1278.

47. Medvedev AV, Robidoux J, Bai X, Cao W, Floering LM, Daniel KW, Collins S: Regulation of the uncoupling protein-2 gene in INSI beta-cells by oleic acid. J Biol Chem 2002, 277:42639-42644.

48. Rim JS, Kozak LP: Regulatory motifs for CREB-binding protein and $\mathrm{Nfe} 2 / 2$ transcription factors in the upstream enhancer of the mitochondrial uncoupling protein I gene. J Biol Chem 2002, 277:34589-34600.

49. Li X, Zhong S, Wong WH: Reliable prediction of transcription factor binding sites by phylogenetic verification. Proc Natl Acad Sci 2005, 102:16945-16950.

50. Dermitzakis ET, Clark AG: Evolution of transcription factor binding sites in Mammalian gene regulatory regions: conservation and turnover. Mol Biol Evol 2002, 19:II|4-1I21.

5I. Arsenijevic D, Onuma H, Pecqueur C, Raimbault S, Manning BS, Miroux B, Couplan E, Alves-Guerra MC, Goubern M, Surwit R, et al.: Disruption of the uncoupling protein-2 gene in mice reveals a role in immunity and reactive oxygen species production. Nat Genet 2000, 26:435-439.

52. Kizaki T, Suzuki K, Hitomi Y, Taniguchi N, Saitoh D, Watanabe K, Onoe K, Day NK, Good RA, Ohno H: Uncoupling protein 2 plays an important role in nitric oxide production of lipopolysaccharide-stimulated macrophages. Proc Natl Acad Sci USA 2002, 99:9392-9397.

53. Rousset S, Alves-Guerra MC, Ouadghiri-Bencherif S, Kozak LP, Miroux B, Richard D, Bouillaud F, Ricquier D, Cassard-Doulcier AM: Uncoupling protein 2, but not uncoupling protein $I$, is expressed in the female mouse reproductive tract. I Biol Chem 2003, 278:45843-45847.

54. Tada T, Endo M, Hirono I, Takashima F, Aoki T: Differential expression and cellular localization of activin and inhibin mRNA in the rainbow trout ovary and testis. Gen Comp Endocrinol 2002, I 25: I 42-149.

55. Samec S, Seydoux J, Dulloo AG: Post-starvation gene expression of skeletal muscle uncoupling protein 2 and uncoupling protein 3 in response to dietary fat levels and fatty acid composition: a link with insulin resistance. Diabetes 1999, 48:436-44I.

56. Samec S, Seydoux J, Russell AP, Montani JP, Dulloo AG: Skeletal muscle heterogeneity in fasting-induced upregulation of genes encoding UCP2, UCP3, PPARgamma and key enzymes of lipid oxidation. Pflugers Arch 2002, 445:80-86.

57. Weigle DS, Selfridge LE, Schwartz MW, Seeley RJ, Cummings DE, Havel PJ, Kuijper JL, BeltrandelRio H: Elevated free fatty acids induce uncoupling protein 3 expression in muscle: a potential explanation for the effect of fasting. Diabetes 1998 47:298-302

58. Matsuda J, Hosoda $\mathrm{K}$, Itoh $\mathrm{H}$, Son $\mathrm{C}$, Doi K, Tanaka T, Fukunaga $Y$, Inoue G, Nishimura H, Yoshimasa $Y$, Yamori Y, Nakao K: Cloning of rat uncoupling protein-3 and uncoupling protein-2 cDNAs: their gene expression in rats fed high-fat diet. FEBS Lett 1997 , 418:200-204.

59. The rainbow trout gene index [http://www.tigr.org/tigr-scripts/ tgi/ $T$ index.cgi?s species $=r$ trout $]$

60. Rexroad CE 3rd, Lee Y, Keele JW, Karamycheva S, Brown G, Koop B, Gahr SA, Palti Y, Quackenbush J: Sequence analysis of a rainbow trout cDNA library and creation of a gene index. Cytogenet Genome Res 2003, 102:347-354.

6I. Soderlund C, Longden I, Mott R: FPC: a system for building contigs from restriction fingerprinted clones. Comput Appl Biosci 1997, 13:523-535.

62. Marra MA, Kucaba TA, Dietrich NL, Green ED, Brownstein B, Wilson RK, McDonald KM, Hillier LW, McPherson JD, Waterston RH: High throughput fingerprint analysis of large-insert clones. Genome Res 1997, 7:1072-1084.

63. The TFSearch: Searching transcription factor binding sites [http://www.cbrc.jp/research/db/TFSEARCH.html] 
64. Olsvik PA, Lie I KK, Jordall AEO, Nilsen TO, Hordvik I: Evaluation of potential reference genes in real-time RT-PCR studies of Atlantic salmon. BMC Molecular Biology 2005, 6:2I.

65. Rutledge RG, Cote C: Mathematics of quantitative kinetic PCR and the application of standard curves. Nucleic Acids Res 2003, 3I:e93.

66. Multiple sequence alignment by Clustal W [http://clus talw.genome.jp/]

67. Kumar S, Tamura K, Nei M: MEGA3: Integrated software for Molecular Evolutionary Genetics Analysis and sequence alignment. Brief Bioinform 2004, 5: 150-163.

68. Genedoc 2.6: A Full featured multiple sequence alignment editor, analyser and shading utility for Windows [http:// www.psc.edu/biomed/genedoc]

Publish with Bio Med Central and every scientist can read your work free of charge

"BioMed Central will be the most significant development for disseminating the results of biomedical research in our lifetime. "

Sir Paul Nurse, Cancer Research UK

Your research papers will be:

- available free of charge to the entire biomedical community

- peer reviewed and published immediately upon acceptance

- cited in PubMed and archived on PubMed Central

- yours - you keep the copyright

Submit your manuscript here:

http://www.biomedcentral.com/info/publishing_adv.asp
BiolMedcentral 